\title{
ANÁLISE DA VAZÃO NO CÓRREGO DA ESTIVA SOB INFLUENCIA DE CANAIS DERIVADOS MULTIFUNCIONAIS
}

\author{
Renato Emanuel Silva ${ }^{(1)}$, Vinicius de Oliveira Maruschi ${ }^{(2)}$, Silvio Carlos Rodrigues ${ }^{(3)}$ \\ (1) Aluno Programa de Pós-graduação em Geografia/Universidade Federal de Uberlândia, renato.logan@gmail.com \\ (2) Aluno de graduação em Geografia/Universidade Federal de Uberlândia, vinicius.maruschi@ufu.br \\ (3) Professor Doutor do Instituto de Geografia/ Universidade Federal de Uberlândia, silgel@ufu.br
}

\section{EIXO: BACIAS HIDROGRÁFICAS E RECURSOS HÍDRICOS: ANÁLISE, PLANEJAMENTO E GESTÃO}

\begin{abstract}
Resumo
Os sistemas de drenagem de bacias hidrográficas, com canais de pequena ordem, podem sofrer alterações a partir de obras para transposição de água. São aos casos de construção de regos d'água, a partir de açudes, que desviam parte ou totalidade da água para áreas de consumo, sendo importante conhecer como se dão tais processos e os impactos que representam. Logo é objetivo deste estudo, investigar como canais abertos artificiais, alteram a dinâmica hidrológica de uma bacia hidrográfica no bioma cerrado. Para tanto foram realizadas 12 atividades de campo que permitiram a obtenção das vazões nos cursos naturais e artificiais afim de revelar os impactos sofridos por estes sistemas de drenagem. Ao longo do estudo, tornou-se evidente que o período da seca apresenta comprometimento da vazão em ao menos dois trechos dos canais naturais em favor do atendimento das derivações multifuncionais. Resultados que implicam na necessidade de correções na maneira como esta cultura de transposição é gerida.
\end{abstract}

Palavras chave: curso fluvial natural e artificial; hidrogeomorfologia; vazão mínima; serviço ecossistêmico

\section{Introdução}

Propriedades rurais tradicionais são servidas, principalmente no Brasil, por canais abertos artificiais, popularmente chamados de regos d'água, Estes cumprem uma série de demandas que permitem o desenvolvimento econômico e social destes locais. Pela grande variedade de serviços realizados, como irrigação, piscicultura, atendimento humano e animal, ornamentação, lazer entre outros, consideramos o mesmo como canais derivados multifuncionais, termo que reúne tais características tão diversas.

Embora seja reconhecida a importância destas estruturas, também é necessário considerar que as mesmas são geradoras de impactos, principalmente na rede de drenagem e na dinâmica ecossistêmica dos ambientes alterados. Desta forma, é objetivo deste trabalho apresentar como uma bacia, com canal de segunda ordem, sofre impactos a partir da inclusão de derivações multifuncionais para sua vazão e os reflexos possíveis a partir destas mudanças. 


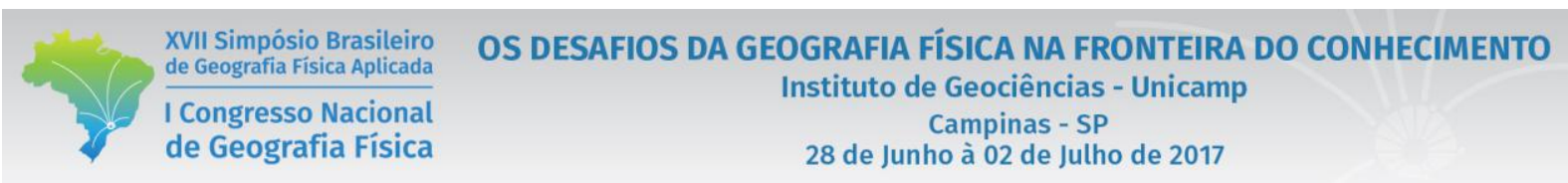

Como espaço para esta pesquisa foi escolhida a bacia do córrego da Estiva, afluente formador do rio Dourados, este tributário da margem esquerda da bacia do rio Paranaíba. A bacia em questão encontra-se distante apenas três quilômetros da sede administrativa do município de Patrocínio-MG (Figura 1) na mesorregião do Triangulo Mineiro/Alto Paranaíba. Tratando-se de uma região de cerrado, o clima é tropical semiúmido com duas estações bem definidas, o verão de outubro a março concentra $90 \%$ dos $1500 \mathrm{~mm}$ médios anuais de precipitações. O restante do ano é marcado pela estação seca, quando os cursos fluviais têm suas vazões consideravelmente reduzidas de modo que a exigência de propriedades rurais em derivar volumes de água para consumo assume contornos delicados.

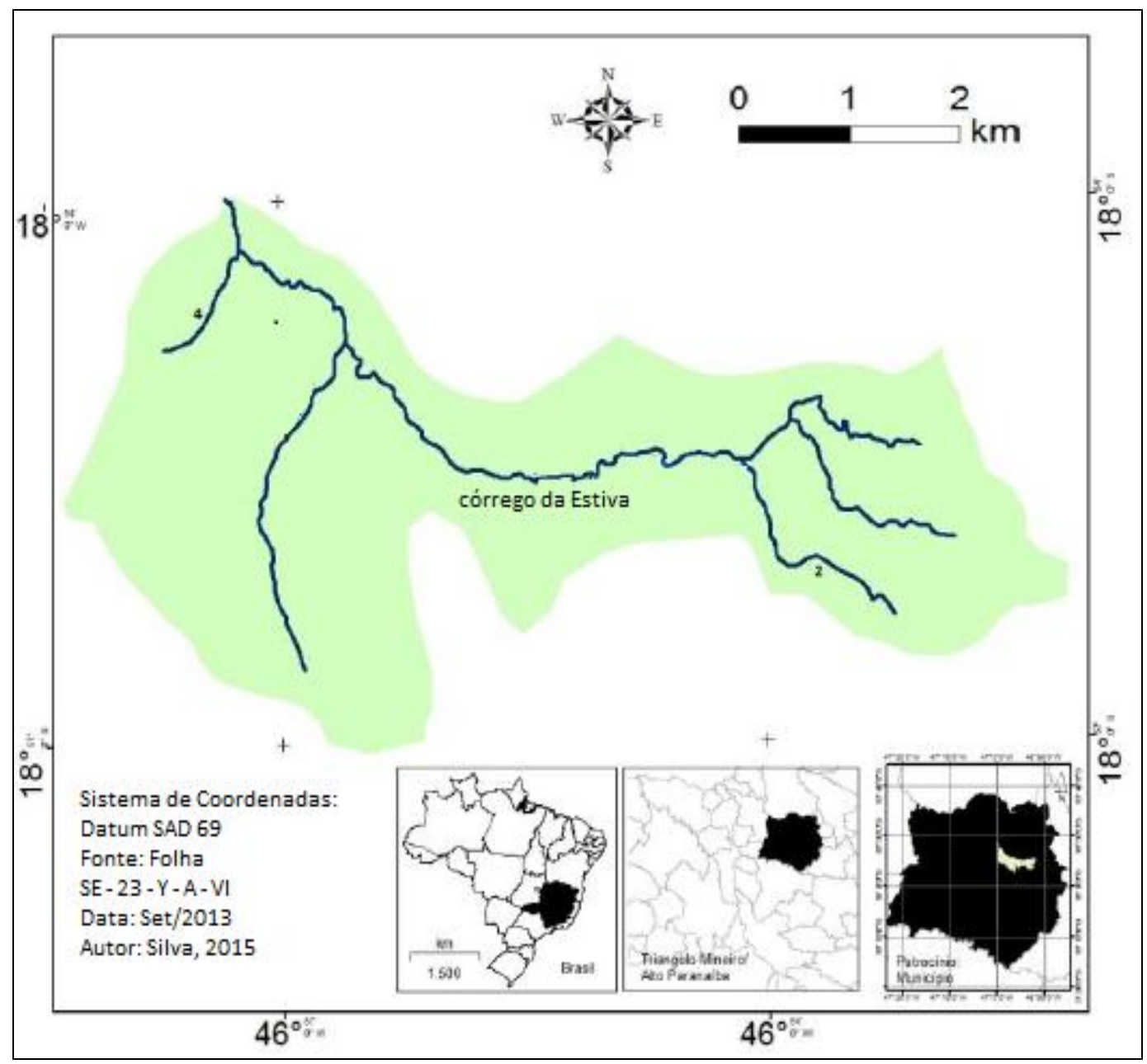

Figura 1: Localização da área de estudo. 


\section{Referencial teórico}

As bacias rurais, de maneira especial as pequenas, são condicionadas as demandas de seus moradores, portadores de meios tradicionais de apropriação e transformação dos espaços. Em ambientes de agricultura tradicional, os solos são ocupados pela agropecuária, cercas são instaladas, curvas de níveis arranjadas, estradas abertas e reformadas, canais fluviais sofrem intervenções, terrenos são drenados (Silva et al, 2007 e Silva, 2014). As alterações apresentadas podem ser notadas na maneira como a bacia passa a responder hidrologicamente. Por isso, como sugerem Tucci e Mendes (2006) às medições realizadas em um determinado ponto da bacia, apontam aspectos de suas condições a montante daquele local, tanto nas vertentes quanto nos canais fluviais (Rocha e Tommaselli, 2012).

Entre estas possibilidades, os canais derivados multifuncionais podem contribuir para mudanças nas vertentes, funcionando como assinaturas topográficas (Tarolli e Sofia, 2016) influindo nos fluxos nestas áreas. Estas interferências junto à conectividade hidrológica já foram observadas em outros estudos (CROCKE e MOCKLER, 2001; MAAS e BROOKES 2009; SIDLE e ONDA 2004), mas é necessário ainda discuta-la a partir da ótica dos canais artificiais de transposição de água, a exemplo do que já foi realizado para canais de drenagem como em Robinson (1990). Ao considerar estes canais como importantes elementos de intervenções eles passam a figurar entre os meios de artificialização de sistemas de drenagem, como estradas, drenos e meios de artificialização de canais naturais (CROCKE et al., 2005; THORP et al., 2009; POOLE, 2010).

No caso do desvio de águas, os canais naturais podem ter comprometidas suas vazões mínimas necessárias para manterem os ecossistemas que comportam (BENETTI, LANNA E COBALCHINI, 2003). Nestes casos, inclusive, podem ser comprometidos os habitats fluviais prejudicando a fauna e flora (BELLETTI et al, 2017). Contudo é possível que ocorram transferências de algumas espécies para estes canais, gerando novos habitats ou prolongando as características dos habitats fluviais originais. A consideração destes impactos tem sido apontados em canais maiores como no caso dos estudos da comunidade bentônica do canal do rio Piumhi (SOUZA e RIBEIRO 2004; FILHO e BUCKUP, 2005, NEVES e CARDOSO, 2009).

$\mathrm{Na}$ Europa, pequenos canais chamados de regadio, semelhantes aos encontrados no Brasil, são amparados por legislações modernas que buscam mantê-los funcionais para que sirvam tanto a questões socioculturais, quanto a ecossistêmicas (LEIBUNDGUT, 1970, 1993 e LEIBUNDGUT e KOHN, 2014). Isto ocorre também pelo longo e intenso histórico de apropriação fluvial e das terras úmidas europeias que torna difícil diferenciar canais naturais de artificiais, como observou Comiti (2011) em canais alpinos, sendo então necessário buscar meios de preservações para todas estas configurações. 
Em âmbito nacional, no Brasil importa a lei das águas (lei nº 9.433 de 1997) que legisla sobre a gestão dos recursos hídricos, deixando clara a prioridade para a manutenção dos ecossistemas aquáticos, estabelecendo normas de gestão inclusive para sistemas de derivação de água os quais devem ser acompanhados por órgãos competentes elegidos em cada um dos estados da Federação. Desta forma, os valores mínimos de vazão, reconhecidos como as menores vazões de sete dias em um período de retorno de /10 anos (Q7/10) nunca devem ser comprometidos nos canais naturais.

Logo os canais derivados multifuncionais precisam ser considerados pelo órgão competente de outorga para que os mesmos atendam as demandas humanas sem comprometimento das necessidades ambientais. A legislação funciona neste caso inclusive como um meio para, no caso de outorgas compartilhadas, mediar conflitos e atenuar impactos negativos entre os diferentes usuários.

\section{Procedimentos metodológicos}

O trabalho partiu de uma revisão bibliográfica sobre impactos ecossistêmicos e sociais em bacias que sofreram intervenções humanas, de maneira especial os ambientes com especificas intervenções, representadas pelos canais artificiais. Na oportunidade foram investigados como tais canais são geridos em ambientes diferentes do Brasil, como no caso europeu. Também a lei brasileira das águas (9.433 de 1997) foi consultada para melhor compreensão dos aspectos da gestão do recurso e como tal lei protege os ecossistemas de algum modo atingidos.

Foram realizadas 12 atividades de campo ao longo do ano hidrológico de outubro de 2015 a setembro de 2016, definido conforme Silva (2014) como o período de sucessão das estações seca e chuvosa para aquela bacia. Assim no início de cada mês um campo era realizado para observação das condições dos canais naturais e dos artificiais a eles atrelados. Também foi realizado um levantamento das vazões nos canais naturais e derivados no córrego da Estiva e em dois de seus canais derivados considerando tal realidade representativa do restante da bacia. Outros pontos foram aferidos visualmente quanto à supressão total das vazões em trechos de cursos naturais.

As vazões foram obtidas pela medição a vau com relação da área da seção molhada e velocidade do fluxo, medida por meio do micromolinete fluviométrico (Global Water BC 1200), tendo sido definida, por batimetria, as seções molhadas na quais foram realizadas medições da velocidade do fluxo, os pontos amostrais variavam conforme a largura e profundidade da seção. Foram considerados como pontos amostrar os pontos nos canais fluviais naturais antes e depois da derivação e o ponto inicial de cada derivação (figura 2). 


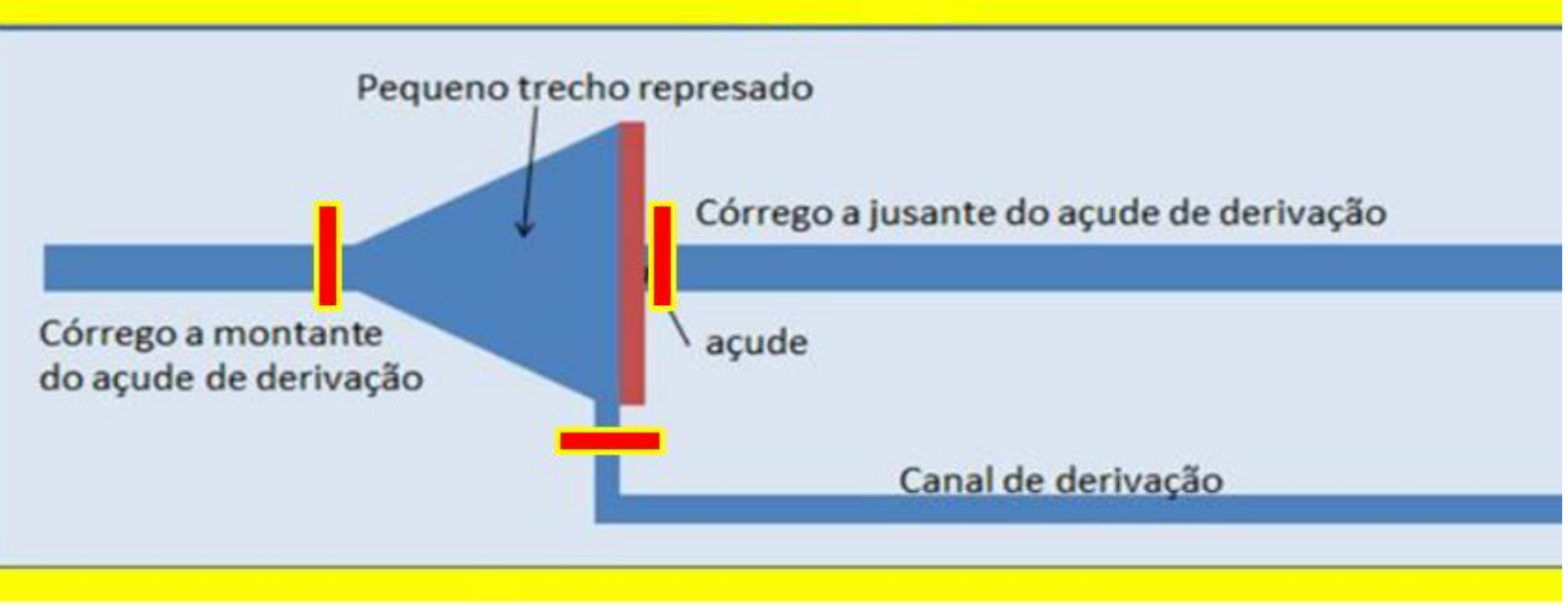

\section{Locais de medição da vazão}

Figura 2: seções parara medição de vazão

\section{Resultados e Discussões}

A figura 3 apresenta a síntese dos valores de vazão, em m³/s, nos pontos avaliados, sendo possível notar que os canais de derivação são coletores de volumes consideráveis de água Sendo que em alguns períodos ocorre a coleta total do volume de água do córrego da Estiva.

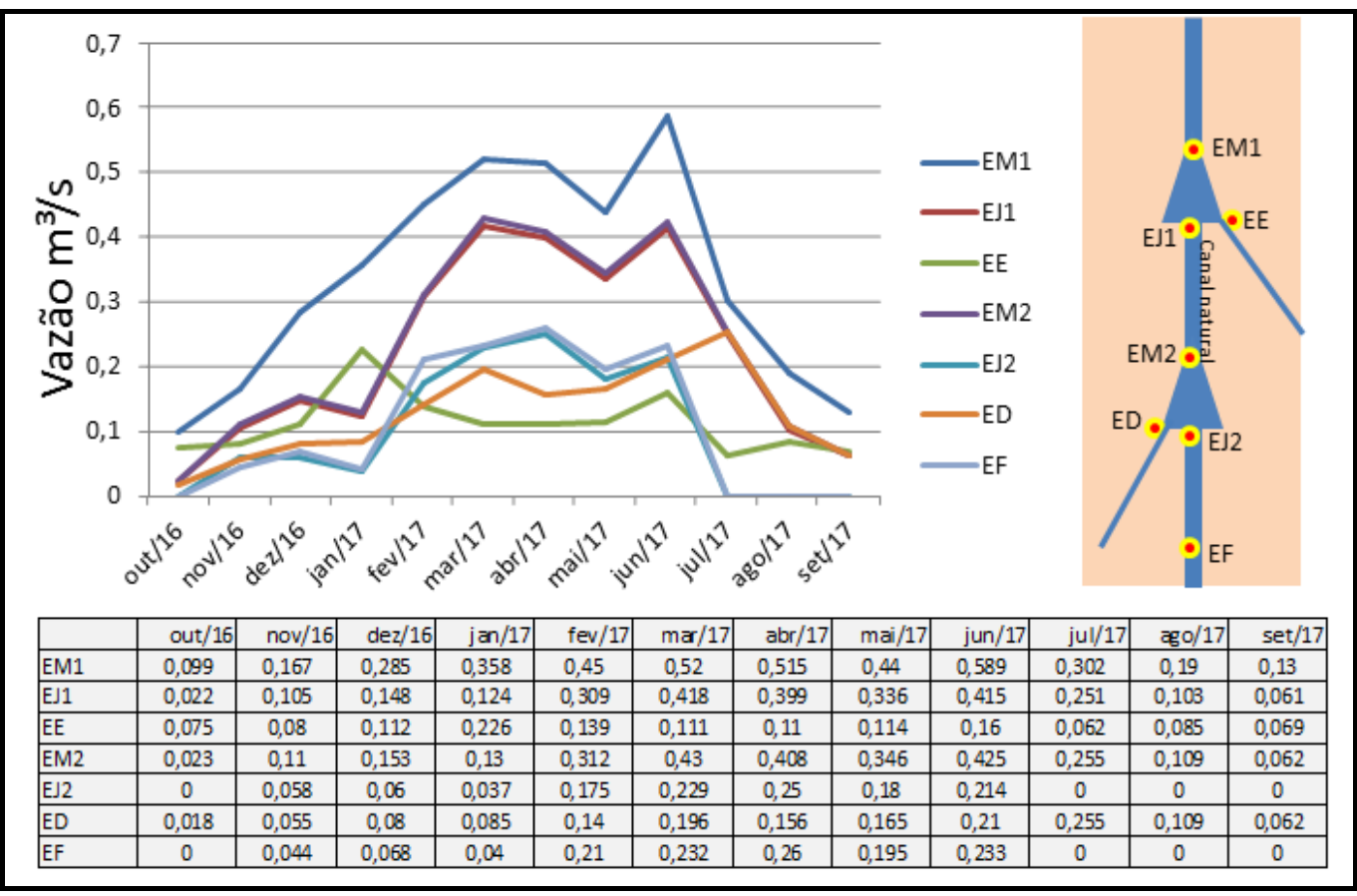

Figura 3: vazões para os cenários levantados no ano hidrológico de 2015/2016 


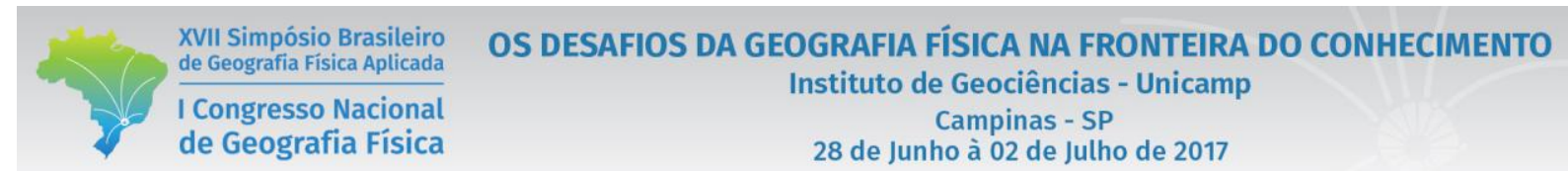

É fato que as vazões direcionadas para ED geram, no período mais seco, de julho a setembro, um desvio total das águas do canal natural, porém a derivação EE também contribuiu para esta condição. Como resultado o trecho desprovido de vazão perde suas condições ecossistêmicas regulares comprometendo, além de espécies vegetais, também insetos, peixes, anfíbios, aves e mamíferos. A figura 4 apresenta a condição encontrada na época mais seca do ano, quando o canal artificial encontra-se com a vazão total do curso natural, este aparece com o leito seco, comprometendo suas funções ecológicas mínimas.

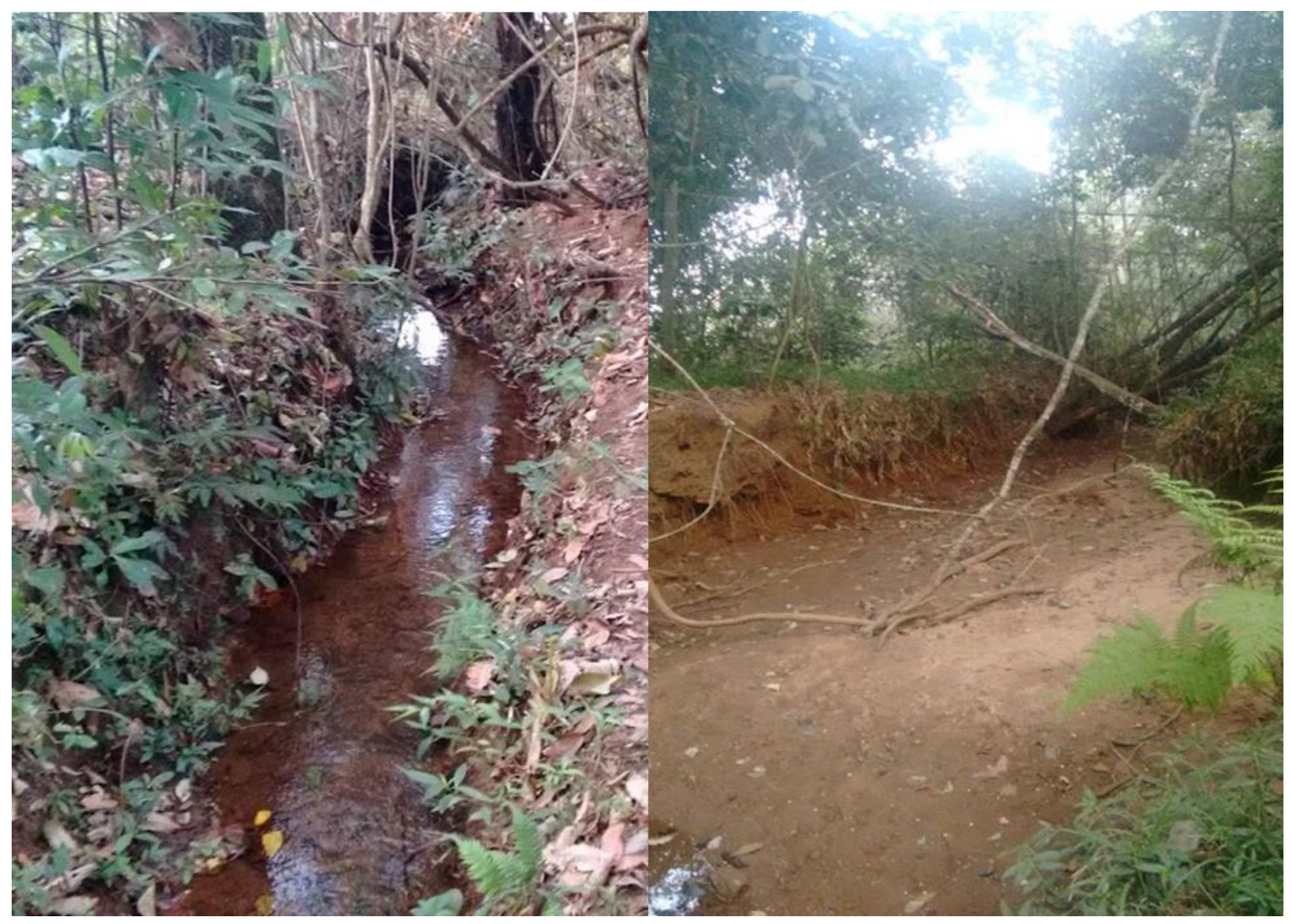

Figura 4: condições hidrológicas para cana artificial e natural no período da seca.

Considerando toda a bacia do córrego da Estiva é possível notar impactos em outro canal, afluente do córrego da Estiva que também tem suas vazões suprimidas entre junho e outubro (figura 5). Neste caso as derivações apresentadas no gráfico de vazões (C e B) se comportam de modo semelhante à derivação D que suprime a vazão de um trecho do córrego do Mariano. 
A solução para este cenário passa por uma melhor gestão do uso da água, é necessário o trabalho com envolvimento dos usuários de modo que os mesmos realizem a manutenção correta e com periodicidade suficiente para evitar perdas hídricas por vazamento e evapotranspiração. Para que os volumes necessários para atender as propriedades sejam assim menores, permitindo que os fluxos sigam perenes no curso natural, como é previsto pela legislação das águas (9.433), como ocorre na derivação A, que tem tido boa manutenção e não retira volumes significativos do córrego da Estiva.

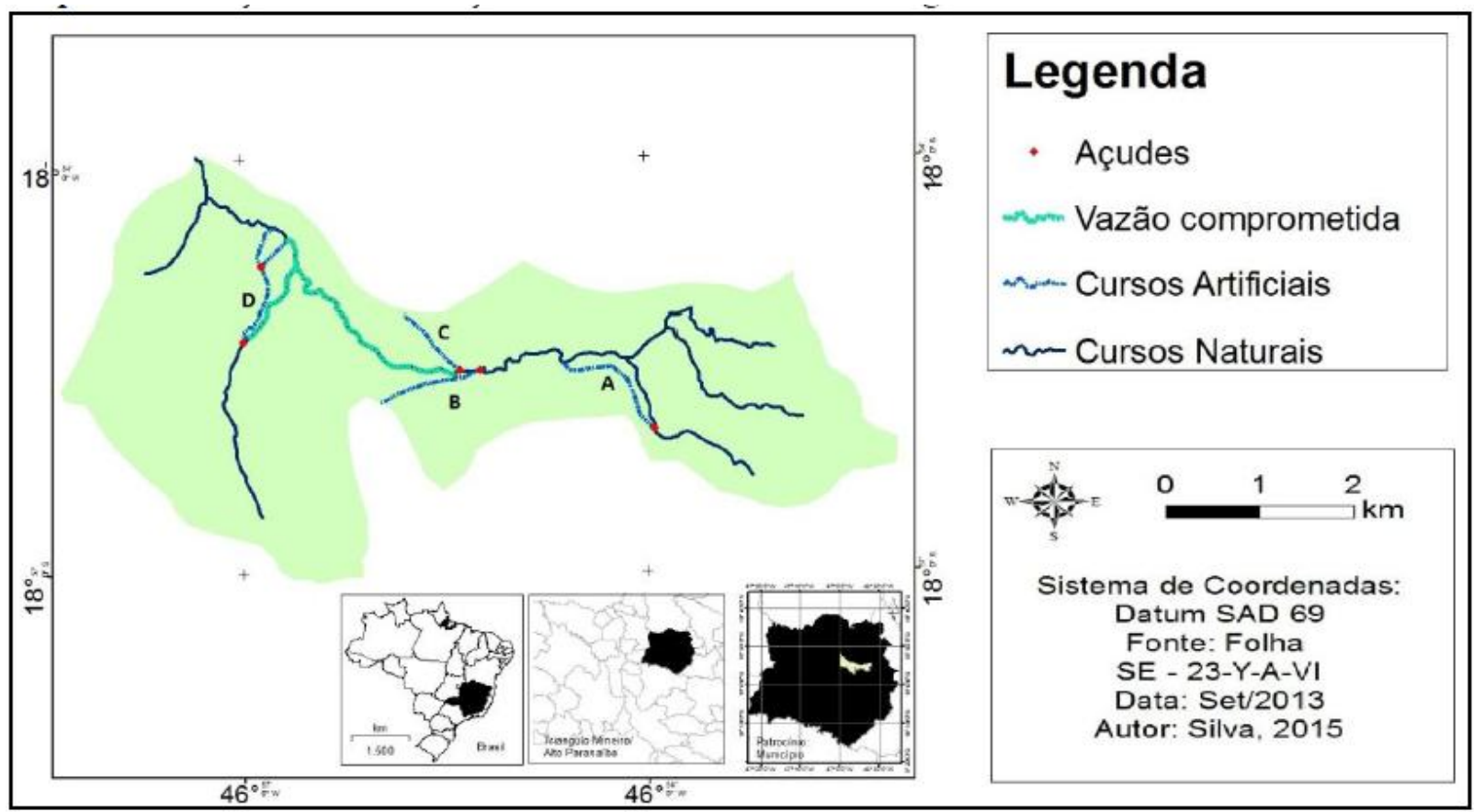

Figura 5: perfil das derivações na bacia do córrego da Estiva.

\section{Considerações finais}

Como mostrado, neste estudo a gestão incorreta dos canais derivados multifuncionais é problemática. Contudo os regos d'agua poderiam desempenhar também papel ecossistêmico semelhante aos casos observados na Europa. Naquele continente a existência de esforços para enquadrar melhor estes canais em projetos de lei e gestão para que os mesmos sigam a valorizar expressões culturais e funcionem como extensões ecossistêmicas dos cursos naturais. Na Europa, 


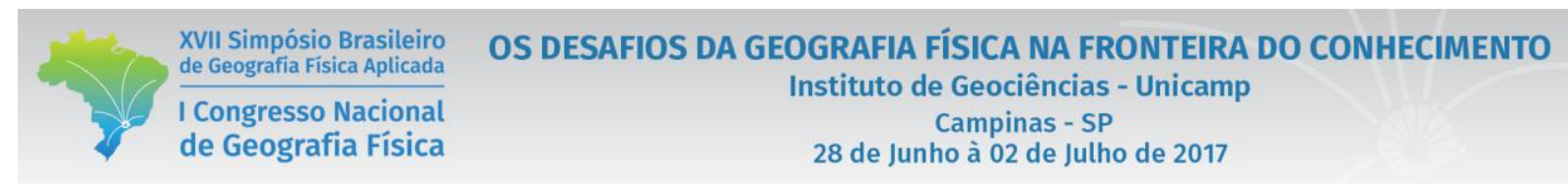

como considera o nível de intervenção humana é tamanho que torna difícil classificar canais fluviais como naturais ou artificiais, o que justifica esse olhar de interesse ambiental também nas ramificações artificiais dos sistemas de drenagem. Os resultados apresentados evidenciam a necessidade de uma revisão no sistema de gestão brasileiro em nome de uma maior constância nas fiscalizações de modo que estes canais cumpram seus papeis, sem danos mais sérios aos ecossistemas.

\section{Agradecimentos}

Agradecem, os autores, a FAPEMIG por apoio financeiro para a participação neste evento. O primeiro autor agradece a CAPES por concessão de bolsa junto ao Programa de Pós-graduação do Instituto de Geografia (IG/UFU).

\section{Referencias}

Belletti, B. et al, Characterising physical habitats and fluvial hydromorphology: A new system for the survey and classification of river geomorphic units. Geomorphology Volume 283, 15 April 2017, Pages 143-157

Benetti, A.D, Lanna, E., e Cobalchini, M. S. Metodologias para Determinação de Vazões Ecológicas em Rios BRH Revista Brasileira de Recursos Hídricos Volume 8 n.2 Abr/Jun 2003, 149-160

COMITI, F. How natural are Alpine mountain rivers? Evidence from the Italian Alps. Earth Surface Processes And Landforms, p. $1-15,2011$

CROCKE, J.; MOCKLER, S. Gully initiation and road-to-stream linkage in a forested catchment, southeastern Australia. Earth Surface Processes and Landforms, v. 26, p. 205-217, 2001.

CROCKE, J.; MOCKLER, S.; FOGARTY, P.; TAKKEN, I. Sediment concentration changes in runoff pathways from a forest road network and the resultant spatial pattern of catchment connectivity. Geomorphology, v. 68, n. 34, p. 257-268, 2005.

FILHO, O. M.; BUCKUP, P. A. A poorly known case of watershed transposition between The são Francisco and upper Paraná River basins. Neotropical ichthyology, 3(3) 449 - 452, 2005.

Lei 9.433, de 8 de Janeiro de 1997. Institui a Política Nacional de Recursos Hídricos. Disponível em: http://www.planalto.gov.br/ccivil_03/LEIS/19433.htm Acesso em: 15 de set. 2013

LEIBUNDGUT, C. ; KOHN, I. European traditional irrigation in transition part i: irrigation in times past-a historic land use practice across Europe. Irrig. and Drain. 63 p. 273-293, 2014

LEIBUNDGUT C. Die Wässermatten des Oberaargaus. Jahrbuch des Oberaargau 13: 163-186. JahrbuchVereinigung Oberaargau: Herzogenbuchsee. 13: 163-186, 1970

LEIBUNDGUT C. Wiesenbewässerungs systeme im Langetental—6 Kartenblätter mit Erläuterungen. Geographica Bernensia 41, 1993

MAAS, S.; BROOKES, A. Fluvial geomorphology, FCERM Londres, 2009. 
NEVES, C.; CARDOSO, A. P. A experiência internacional com projetos de transposição de água - lições para a do rio São Francisco. XXIX Encontro Nacional de Egenharia de produção. Salvador. 2009.

POOLE, G. C. Stream hydrogeomorphology as a physical science basis for advances in stream ecology. J. N. Am. Benthol. Soc., v.29. 12-25. 2010.

ROBINSON, M. Impact of improved land drainage on river flows. Institute of Hydrology. Wallingford. p. 233, 1990.

SIDLE, R. C.; ONDA, Y. Hydrogeomorphology: overview of an emerging Science. Hydrological processes. 18, 597-602. 2004. Disponivel em: www.interscience.wiley.com. Acesso em: 09/02/2016.

SILVA, A. M.; SCHULZ, H.E; CAMARGO, P.B. Erosão e Hidrossedimentologia em bacias hidrográficas. São Carlos, 2007. $2^{\mathrm{a}}$ edição.

SILVA, R. E. Disponibilidade e demanda hídrica a partir da análise ambiental da região do alto curso do rio Dourados em Patrocínio (mg). Uberlândia: UFU, 2014. (Dissertação de Mestrado)

SOUZA, J. A.; RIBEIRO, E. Transposição do rio São Francisco e seus efeitos sobre o território. VII CBG, 2004.

THORP, J. H. The Riverine Ecosystem Synthesis Toward Conceptual Cohesiveness in River Science. Elsevier Inc. Amsterdam. 233 p. 2009.

TAROLI, P.; SOFIA, G. Human topographic signatures and derived geomorphic processes across landscapes.

Geomorphology, v. 255, p. 140-161, 2016.

TUCCI, C.E.M.; MENDES, C.A. Curso de Avaliação Ambiental Integrada de Bacia. Brasília - DF: RHAMA. 2006 Rocha e Tommaselli, 2012). 